\title{
Enhancing Neuroplasticity to Augment Cognitive Remediation in Schizophrenia
}

\author{
Carol Jahshan ${ }^{1,2 *}$, Yuri Rassovsky ${ }^{2,3}$ and Michael F. Green ${ }^{1,2}$ \\ ${ }^{1}$ VISN-22 Mental IIIness Research, Education and Clinical Center (MIRECC), VA Greater Los Angeles Healthcare System, \\ Los Angeles, CA, United States, '2Department of Psychiatry and Biobehavioral Sciences, David Geffen School of Medicine, \\ University of California, Los Angeles, Los Angeles, CA, United States, ${ }^{3}$ Department of Psychology, Gonda Multidisciplinary \\ Brain Research Center, Bar-llan University, Ramat-Gan, Israel
}

\section{OPEN ACCESS}

Edited by:

Tomiki Sumiyoshi, National Center of Neurology and Psychiatry, Japan

Reviewed by:

Zui Narita,

Tokyo Regional Correction

Headquarters, Japan

Satoru Ikezawa,

Japan Agency for Medical Research Promotion, Japan

*Correspondence: Carol Jahshan carol.jahshan@ucla.edu

Specialty section:

This article was submitted to Psychopathology,

a section of the journal

Frontiers in Psychiatry

Received: 05 July 2017 Accepted: 15 September 2017 Published: 27 September 2017

Citation:

Jahshan C, Rassovsky Y and

Green MF (2017) Enhancing

Neuroplasticity to Augment Cognitive

Remediation in Schizophrenia.

Front. Psychiatry 8:191.

doi: 10.3389/fpsyt.2017.00191
There is a burgeoning need for innovative treatment strategies to improve the cognitive deficits in schizophrenia. Cognitive remediation (CR) is effective at the group level, but the variability in treatment response is large. Given that CR may depend on intact neuroplasticity to produce cognitive gains, it is reasonable to combine it with strategies that harness patients' neuroplastic potential. In this review, we discuss two non-pharmacological approaches that can enhance neuroplasticity and possibly augment the effects of CR in schizophrenia: physical exercise and transcranial direct current stimulation (tDCS). Substantial body of evidence supports the beneficial effect of physical exercise on cognition, and a handful of studies in schizophrenia have shown that physical exercise in conjunction with $\mathrm{CR}$ has a larger impact on cognition than $\mathrm{CR}$ alone. Physical exercise is thought to stimulate neuroplasticity through the regulation of central growth factors, and current evidence points to brain-derived neurotrophic factor as the potential underlying mechanism through which physical exercise might enhance the effectiveness of CR. tDCS has emerged as a potential tool for cognitive enhancement and seems to affect the cellular mechanisms involved in long-term potentiation (LTP). A few reports have demonstrated the feasibility of integrating tDCS with CR in schizophrenia, but there are insufficient data to determine if this multimodal approach leads to incremental performance gain in patients. Larger randomized controlled trials are necessary to understand the mechanisms of the combined tDCS-CR intervention. Future research should take advantage of new developments in neuroplasticity paradigms to examine the effects of these interventions on LTP.

Keywords: schizophrenia, cognitive training, remediation, physical exercise, transcranial direct current stimulation, neuromodulation, neuroplasticity, brain-derived neurotrophic factor

\section{INTRODUCTION}

Antipsychotic medications are useful in ameliorating positive symptoms of schizophrenia, but they have little effect on cognitive deficits $(1,2)$. Efforts to improve cognitive deficits in schizophrenia are of paramount importance as they are among the strongest predictors of patients' functional outcome (3). Most of the efforts for cognition enhancement have used pharmacological approaches (i.e., drugs that enhance learning and memory in animal models) (4). However, the results in larger trials have 
been disappointing, and currently, there is no drug approved for cognition enhancement in schizophrenia (5). Therefore, treatment studies in this population have started to shift to cognitive remediation (CR) strategies. Although CR in schizophrenia is effective at the group level $(6,7)$, there is substantial individual variability in treatment response, and many patients exhibit little benefit (8). Moreover, the training effects resulting from CR alone do not always generalize to improvements in real-life functioning (9). Thus, as the best validated treatment for the cognitive dysfunction in schizophrenia, CR only leads to a moderate effect-size improvement in cognition (0.45), with an even lower impact on daily functioning $(0.36)(6,9)$. It is, therefore, critical to consider ways of enhancing the impact of CR.

Recently, "neuroplasticity-based" interventions have been developed to train perceptual processes in schizophrenia, while also engaging attentional and working memory operations (10). These interventions are explicitly designed to drive adaptive plastic changes throughout distributed prefrontal-temporoparietal systems (11). Many studies in schizophrenia patients have demonstrated that this neuroscience-informed approach to training generates meaningful restoration of prefrontal functions and higher-order cognition (12-14), with associated improvements in community functioning (15). Thus, neuroplasticity may be an important mechanism underlying effective intervention approaches. However, this CR method requires lengthy hours of repetitive, intensive practice to induce significant changes. Combining $\mathrm{CR}$ with strategies that promote neuroplasticity may not only lead to larger and longer-lasting improvements, but also require shorter training protocols. Although there have been efforts to combine $\mathrm{CR}$ with cognitive-enhancing medications that affect neuroplasticity, such as D-cycloserine (16) and modafinil (17), less attention has been devoted to non-pharmacological approaches that could potentially augment CR effects and maximize improvements in functional outcomes. In this brief review, we will discuss two recent non-pharmacological approaches that are thought to enhance neuroplasticity in schizophrenia: physical exercise and transcranial direct current stimulation (tDCS). It should be noted that there are many other neurostimulation techniques that have been discussed in the literature, such as transcranial magnetic stimulation (TMS), transcranial electrical stimulation (TES), magnetic seizure therapy, vagus nerve stimulation, and deep brain stimulation. However, only tDCS has been combined with CR.

\section{REVIEW OF PHYSICAL EXERCISE AND tDCS STUDIES}

\section{Physical Exercise and Cognition}

The beneficial effects of physical exercise on cognition are well documented in healthy individuals, as well as across many medical and psychiatricillnesses (18-20). Accumulating evidence suggests that exercise reduces pro-inflammatory processes and peripheral risk factors (i.e., obesity and diabetes) that are associated with cognitive decline (21). Furthermore, it stimulates hippocampal neuroplasticity and promotes angiogenesis, neurogenesis, and synaptogenesis through the regulation of central growth factors
(22). The mechanisms of exercise-induced cognitive improvements seem, to a large extent, to be related to an increased production of brain-derived neurotrophic factor (BDNF), which plays a pivotal role in synaptic plasticity and is particularly important for learning and memory $(18,23,24)$. Similar to CR (25), exercise (26) has been shown to increase peripheral BDNF levels.

As the two approaches could potentially enhance cognition through overlapping neurobiological mechanisms, adding exercise to a CR program may further harness patients' neuroplastic potential and lead to cognitive gains beyond that achieved by $\mathrm{CR}$ alone. The evidence from animal research suggests some benefit from combining these approaches. Fabel et al. (27), for example, showed that a combination of aerobic exercise and cognitive enrichment for rodents had beneficial effects on neurogenesis, leading to a $30 \%$ greater increase in new neurons than either activity alone. Several reports in healthy older adults have compared the separate vs. combined effects of CR and exercise and shown superior effects of the combined intervention on verbal/working memory $(28,29)$, divided attention (30), as well as global cognitive performance and everyday functioning (31). Studies in children (32) have also shown that training programs that integrate physical exercise with computer-based training games improved learning and increased gains on school-administered math and reading achievement tests.

\section{Physical Exercise in Schizophrenia}

Physical activity has been shown to ameliorate the psychotic and negative symptoms of schizophrenia and improve patients' quality of life by reducing health problems often associated with the illness $(33,34)$. Randomized controlled trials (RCTs) have been published recently demonstrating that physical exercise, especially aerobic exercise, improves cognitive functioning in schizophrenia patients, with corresponding increases in white matter integrity and structural connectivity (35), hippocampal volume (36), and BDNF signaling (37). A recent meta-analysis (38) identified 10 trials (7 RCTs and 3 non-randomized studies) evaluating the cognitive effects of exercise in schizophrenia. Pooled effect sizes across all outcomes showed that exercise significantly improved cognition (particularly attention, working memory, and social cognition) more than the control conditions. The treatment effect size of $0.33(95 \% \mathrm{CI}=0.13-0.53, p=0.001)$ across all studies and $0.43(95 \% \mathrm{CI}=0.21-0.66, p<0.001)$ in RCTs suggests that the beneficial effect of exercise on cognition in schizophrenia is comparable to that of CR.

\section{Physical Exercise plus CR in Schizophrenia}

We are aware of three published studies that have combined CR and exercise in schizophrenia. In one study (39), 29 patients were randomly assigned to either CR and exercise or CR and mental relaxation. The interventions were 4 -week long and consisted of three weekly sessions ( $30 \mathrm{~min}$ of CR and $45 \mathrm{~min}$ of either aerobic exercise or relaxation). Both groups showed cognitive gains in the domains of processing speed, working memory, and visual learning, improvement in subjective well-being, and reduction 
in negative symptoms. However, the effects were superior for the combined cognitive and physical training group.

In another study (40), 22 patients were enrolled in a 12-week endurance-training program augmented with CR and compared to a matched control group. Patients in the endurance training group exercised on bicycle ergometers, while those in the control group played table soccer for 30 min three times a week. After 6 weeks of the intervention period, CR was added in each group, for two 30 min-sessions a week. Results showed that, compared to the control condition, endurance training and CR significantly improved short- and long-term verbal memory, cognitive flexibility, global and social functioning, and negative symptoms. Unfortunately, the lack of random assignment, baseline differences between the groups, and the fact that the cognitive and clinical improvement in the combined training group was only seen after CR was added to the intervention make the findings difficult to interpret.

Last, a pilot study of recent-onset schizophrenia patients randomly assigned participants to 10 weeks of CR and exercise $(n=7)$ or CR alone $(n=9)$ (41). The CR intervention consisted of $2 \mathrm{~h}$ of auditory and social cognitive training twice/week, and exercise consisted of 30-45 min of aerobic conditioning 4 days/ week. Results showed that the differential gains in global cognition and functional outcome were larger in the combined intervention group relative to the CR group, with Cohen's $f$ effect sizes of 0.48 for the MCCB overall composite and 0.88 for independent living skills.

\section{tDCS and Cognition}

In recent years, neurostimulation has been developed as a non-invasive tool for cognitive enhancement $(42,43)$, with a primary advantage of having fewer side effects than pharmacological treatment (44). Unlike other brain stimulation techniques (e.g., TMS, TES), tDCS uses a weak electrical current (1-2 mA) to alter spontaneous neuronal network activity by shifting membrane potentials in a hyperpolarizing or depolarizing direction without inducing neuronal firing (45-47). tDCS changes the excitability of neurons in a polarity-dependent manner (48), such that anodal stimulation enhances cortical excitability, whereas cathodal stimulation decreases it (49). Various electrode montages can be applied to the scalp to modulate different areas of activity in the brain. Although tDCS has coarse spatial targeting, a few minutes of stimulation can lead to changes in cortical excitability lasting for over an hour (50).

The therapeutic effect of tDCS is thought to stem from its impact on the cellular and molecular mechanisms involved in long-term potentiation (LTP) $(51,52)$, and its after effects seem to be NMDA-receptor dependent (53). Thus, similar to physical exercise (21) and CR (54), tDCS appears to increase cortical plasticity (55) and could have additive or synergistic effects with $\mathrm{CR}$, allowing for better cognitive outcomes.

A handful of studies in healthy samples have administered tDCS during specialized cognitive training and shown a performance-enhancing effect on the trained task (56) and generalization to untrained tasks (57). For instance, Martin et al. (56) demonstrated increased accuracy on a dual-working memory task during concurrent active tDCS vs. sham, but the effect was only present during the stimulation period and did not result in greater subsequent learning. This short-lived "online" effect has also been observed during combined tDCS and behavioral inhibition training (58). Additionally, Andrews et al. (57) found that completing an $n$-back task while receiving tDCS resulted in greater improvement in performance on Digit Span Forward compared to either tDCS or the cognitive activity alone. Similarly, the simultaneous administration of $\mathrm{tDCS}$ and computerized CR in healthy older adults significantly improved working memory compared with CR alone (59). The superiority in performance with this integrated approach was also evident in studies combining multiple repeated tDCS sessions with training on a motor skill task (52) and artificial numerical learning task (60).

\section{tDCS in Schizophrenia}

Most studies examining the effects of tDCS in schizophrenia have administered the stimulation at rest, while the subject is engaged in a passive activity, such as watching a movie, followed by an "offline" assessment of interest. In different randomized shamcontrolled trials, tDCS was found to enhance working memory (61), probabilistic association learning (62), and composite scores on measures of cognition (63), when applied to the left dorsolateral prefrontal cortex. More specifically, Hoy et al. (61) reported significantly better performance over time on a working memory task following a single tDCS session compared to sham $(p=0.027)$. Although Vercammen et al. (62) found no significant effect at the group level, a subgroup of patients with adequate learning at baseline improved with active tDCS. In Smith et al's RCT (63), active compared to sham tDCS subjects showed significant improvements after the fifth tDCS session in the MCCB overall composite $(p=0.008)$ and the working memory $(p=0.002)$ and attention-vigilance $(p=0.027)$ domain scores, with large effect sizes (Cohen's $d$ values ranged from 0.84 to 1.25$)$. There is also evidence that $\mathrm{tDCS}$ can ameliorate auditory hallucinations $(64,65)$ and negative symptoms $(66)$ in patients, as well as modulate the amplitude of the mismatch negativity, an EEG index of basic auditory processing (67).

\section{tDCS plus CR in Schizophrenia}

Schizophrenia researchers have recently begun to investigate the feasibility and efficacy of integrating tDCS and CR. There are currently four published reports in this area, mostly piloting this procedure in small clinical samples. In one study (68), two patients received a neuroplasticity-based CR intervention combined with tDCS and showed cognitive improvements that were maintained at 1-month follow-up. The 4-week intervention consisted of five 45-min auditory training sessions a week with active tDCS administered concurrently with CR on three sessions per week. In another pilot study $(69)$, patients $(n=10)$ received three working memory training sessions a week for 16 weeks, with active or sham tDCS applied during two of the CR sessions each week starting in week 3 . The authors reported enhanced cognitive performance on word and picture N-back tasks and MCCB overall composite when CR was paired with tDCS. In a negative findings study (70), 10 patients were randomized to either active or sham tDCS (10 consecutive sessions over 5 days), with cognitive training (administration of $n$-back and sequence 
learning tasks) randomly applied during one of the tDCS sessions. The combined approach failed to improve clinical symptoms and cognitive performance.

In the largest study to date (71), investigators randomly assigned 49 patients to CR (training on a working memory and implicit learning task) and either active $(n=24)$ or sham tDCS $(n=25)$. The intervention was relatively short and consisted of four cognitive training days (day 1 , day 2 , day 14 , and day 56), with two sessions on each day. tDCS was administered concomitantly with CR during the second session of days 1 and 14. Results showed significantly better working memory performance in the CR and active tDCS group relative to the CR and sham tDCS group. Surprisingly, the improved performance was evident on days 2 and 56, suggesting that tDCS had no enhancing effects during the acute stimulation but rather long-term effects on consolidation and learning.

\section{CONCLUSION AND FUTURE DIRECTIONS}

Based on the aforementioned review, it appears that both physical exercise and tDCS are intriguing candidates for augmenting the therapeutic effects of CR in schizophrenia. Current evidence suggests that a multimodal intervention that combines CR with physical exercise has a larger impact on cognitive functioning than $\mathrm{CR}$ alone. Moreover, there is strong evidence implicating BDNF as the mechanism underlying the cognitive-physical training approach $(30,41)$. Nonetheless, despite the promise that exercise has shown in augmenting CR in schizophrenia, there are several methodological issues that remain unresolved. For example, the literature is not consistent regarding the type, frequency, intensity, and duration of physical training necessary to produce the beneficial effects. Aerobic exercise has been the most studied and has produced the most consistent effects on cognition. However, other types of physical activity, such as yoga $(72,73)$, high-intensity interval training (74), and high-velocity circuit resistance training (75) deserve further attention. Furthermore, although Firth et al. (38) showed that a greater amount of exercise is associated with larger cognitive improvement, Kimhy et al. (76) found that it is the fidelity with target training intensity, rather than the frequency and duration of exercise, which correlates with changes in cognition. Some review studies $(23,72,77)$ suggest a minimum of three sessions per week (at least $30 \mathrm{~min} /$ session) of moderate-intensity aerobic training for schizophrenia patients, administered in a supervised group setting for a minimum of 12 weeks, which is in line with recommendations by the American College of Sports Medicine (78).

In addition to refining optimal exercise training parameters, it is also essential to consider the timing of exercise with respect to $\mathrm{CR}$ when combining the two approaches. For instance, it might be more beneficial to start a treatment session with aerobic exercise followed by $\mathrm{CR}$, as some studies have shown that engaging in physical activity before or while performing a cognitively demanding task improves learning or performance on the task (40). In a recent review (79), the authors proposed that aerobic exercise preceding CR may create a state of neuroplastic readiness in the brain through BDNF upregulation, which can potentiate the effectiveness of CR.
As far as the concurrent administration of $\mathrm{tDCS}$ and CR, emerging data support the feasibility and tolerability of this approach, but additional studies are needed to determine if it leads to performance gain in schizophrenia patients. Although the duration of stimulation of around $20 \mathrm{~min}$ has been consistently employed across studies, the therapeutic dose (i.e., number of sessions per day or week) has yet to be established. A host of parameters may moderate the effects of tDCS on cognitive outcomes, including placement and size of anodal/ cathodal electrodes, unilateral vs. bilateral stimulation, amplitude of stimulation, and selection of training tasks during stimulation. Although it has been suggested that neuromodulation in combination with memory training may enhance the effects of training via LTP (80), the underlying mechanisms of $\mathrm{tDCS}$ have been mainly explored within the motor cortex and not memory-related regions. Therefore, beyond methodological research to identify a standard montage and the parameters required for therapeutic tDCS administration, larger RCTs are necessary to establish efficacy and relevant mechanisms of the combined tDCS-CR intervention.

Both approaches seem to have the potential to enhance the impact of CR by affecting functions that underlie neuroplasticity $(55,81)$. Fortunately, it is now possible to measure neuroplasticity in vivo in humans using neuroimaging techniques (e.g., EEG and fMRI). New paradigms have been recently developed to assess LTP non-invasively using repetitive sensory stimulation. Similar to electrical stimulation in animals (82), repetitive high-frequency stimulation (HFS) can induce LTP-like effects in humans (83-87). Some studies have measured LTP-like plasticity using a paradigm in which visual-evoked potentials (VEPs) to visual stimuli are recorded before and after the same stimulus is presented at a high frequency. Enhancement (increase in amplitude) of the VEPs after HFS is thought to reflect experience-dependent neuroplasticity of the visual cortex $(84,86-88)$. So far, two studies have been published using this EEG paradigm in schizophrenia $(88,89)$. Future treatment studies in schizophrenia should take advantage of these novel, non-invasive methods of assessing neuroplasticity to directly test whether physical exercise or tDCS affect LTP. For example, we are currently conducting an RCT in which a visual LTP paradigm is an outcome measure to examine changes in neuroplasticity following cognitive training.

In the absence of any robust pharmacological treatments for cognitive deficits in schizophrenia, physical exercise and tDCS are feasible and intriguing adjunctive treatments to enhance neuroplasticity and augment the effects of CR. While showing promise, their efficacy still needs to be demonstrated in more rigorously controlled studies.

\section{AUTHOR CONTRIBUTIONS}

CJ performed the literature search and drafted the manuscript. YR and MG critically reviewed the manuscript. All the authors read and approved the final manuscript.

\section{FUNDING}

Writing of this manuscript was supported by a Career Development Award (IK2 CX000844) to the first author from the U.S. Department of Veterans Affairs, Clinical Sciences Research and Development Service. 


\section{REFERENCES}

1. Marder SR. Initiatives to promote the discovery of drugs to improve cognitive function in severe mental illness. J Clin Psychiatry (2006) 67(7):e03. doi:10.4088/JCP.0706e03

2. Keefe RS, Bilder RM, Davis SM, Harvey PD, Palmer BW, Gold JM, et al. Neurocognitive effects of antipsychotic medications in patients with chronic schizophrenia in the CATIE Trial. Arch Gen Psychiatry (2007) 64(6):633-47. doi:10.1001/archpsyc.64.6.633

3. Green MF, Kern RS, Heaton RK. Longitudinal studies of cognition and functional outcome in schizophrenia: implications for MATRICS. Schizophr Res (2004) 72(1):41-51. doi:10.1016/j.schres.2004.09.009

4. Buchanan RW, Keefe RS, Umbricht D, Green MF, Laughren T, Marder SR. The FDA-NIMH-MATRICS guidelines for clinical trial design of cognitive-enhancing drugs: what do we know 5 years later? Schizophr Bull (2011) 37(6):1209-17. doi:10.1093/schbul/sbq038

5. Goff DC, Hill M, Barch D. The treatment of cognitive impairment in schizophrenia. Pharmacol Biochem Behav (2011) 99(2):245-53. doi:10.1016/j. pbb.2010.11.009

6. McGurk SR, Twamley EW, Sitzer DI, McHugo GJ, Mueser KT. A meta-analysis of cognitive remediation in schizophrenia. Am JPsychiatry (2007) 164(12):1791-802. doi:10.1176/appi.ajp.2007.07060906

7. Twamley EW, Jeste DV, Bellack AS. A review of cognitive training in schizophrenia. Schizophr Bull (2003) 29:359-82. doi:10.1093/oxfordjournals.schbul. a007011

8. Corbera S, Wexler BE, Poltorak A, Thime WR, Kurtz MM. Cognitive remediation for adults with schizophrenia: does age matter? Psychiatry Res (2017) 247:21-7. doi:10.1016/j.psychres.2016.10.084

9. Wykes T, Huddy V, Cellard C, McGurk SR, Czobor P. A meta-analysis of cognitive remediation for schizophrenia: methodology and effect sizes. Am J Psychiatry (2011) 168(5):472-85. doi:10.1176/appi.ajp.2010.10060855

10. Vinogradov S, Fisher M, de Villers-Sidani E. Cognitive training for impaired neural systems in neuropsychiatric illness. Neuropsychopharmacology (2012) 37(1):43-76. doi:10.1038/npp.2011.251

11. Keshavan MS, Vinogradov S, Rumsey J, Sherrill J, Wagner A. Cognitive training in mental disorders: update and future directions. Am J Psychiatry (2014) 171(5):510-22. doi:10.1176/appi.ajp.2013.13081075

12. Adcock RA, Dale C, Fisher M, Aldebot S, Genevsky A, Simpson GV, et al. When top-down meets bottom-up: auditory training enhances verbal memory in schizophrenia. Schizophr Bull (2009) 35(6):1132-41. doi:10.1093/ schbul/sbp068

13. Dale CL, Findlay AM, Adcock RA, Vertinski M, Fisher M, Genevsky A, et al. Timing is everything: neural response dynamics during syllable processing and its relation to higher-order cognition in schizophrenia and healthy comparison subjects. Int J Psychophysiol (2010) 75(2):183-93. doi:10.1016/j. ijpsycho.2009.10.009

14. Subramaniam K, Luks TL, Garrett C, Chung C, Fisher M, Nagarajan S, et al. Intensive cognitive training in schizophrenia enhances working memory and associated prefrontal cortical efficiency in a manner that drives long-term functional gains. Neuroimage (2014) 99:281-92. doi:10.1016/ j.neuroimage.2014.05.057

15. Fisher M, Holland C, Subramaniam K, Vinogradov S. Neuroplasticity-based cognitive training in schizophrenia: an interim report on the effects 6 months later. Schizophr Bull (2010) 36(4):869-79. doi:10.1093/schbul/sbn170

16. Cain CK, McCue M, Bello I, Creedon T, Tang DI, Laska E, et al. d-Cycloserine augmentation of cognitive remediation in schizophrenia. Schizophr Res (2014) 153(1-3):177-83. doi:10.1016/j.schres.2014.01.016

17. Michalopoulou PG, Lewis SW, Drake RJ, Reichenberg A, Emsley R, Kalpakidou AK, et al. Modafinil combined with cognitive training: pharmacological augmentation of cognitive training in schizophrenia. Eur Neuropsychopharmacol (2015) 25(8):1178-89. doi:10.1016/j. euroneuro.2015.03.009

18. Gomez-Pinilla F, Hillman C. The influence of exercise on cognitive abilities. Compr Physiol (2013) 3(1):403-28. doi:10.1002/cphy.c110063

19. Marzolini S, Oh P, Mcllroy W, Brooks D. The effects of an aerobic and resistance exercise training program on cognition following stroke. Neurorehabil Neural Repair (2013) 27(5):392-402. doi:10.1177/1545968312465192

20. Nagamatsu LS, Chan A, Davis JC, Beattie BL, Graf P, Voss MW, et al. Physical activity improves verbal and spatial memory in older adults with probable mild cognitive impairment: a 6-month randomized controlled trial. J Aging Res (2013) 2013:861893. doi:10.1155/2013/861893

21. Cotman CW, Berchtold NC, Christie LA. Exercise builds brain health: key roles of growth factor cascades and inflammation. Trends Neurosci (2007) 30(9):464-72. doi:10.1016/j.tins.2007.06.011

22. Lista I, Sorrentino G. Biological mechanisms of physical activity in preventing cognitive decline. Cell Mol Neurobiol (2010) 30(4):493-503. doi:10.1007/ s10571-009-9488-x

23. Malchow B, Reich-Erkelenz D, Oertel-Knochel V, Keller K, Hasan A, Schmitt A, et al. The effects of physical exercise in schizophrenia and affective disorders. Eur Arch Psychiatry Clin Neurosci (2013) 263(6):451-67. doi:10.1007/ s00406-013-0423-2

24. Voss MW, Vivar C, Kramer AF, van Praag H. Bridging animal and human models of exercise-induced brain plasticity. Trends Cogn Sci (2013) 17(10):525-44. doi:10.1016/j.tics.2013.08.001

25. Fisher M, Mellon SH, Wolkowitz O, Vinogradov S. Neuroscience-informed auditory training in schizophrenia: a final report of the effects on cognition and serum brain-derived neurotrophic factor. Schizophr Res Cogn (2016) 3:1-7. doi:10.1016/j.scog.2015.10.006

26. Szuhany KL, Bugatti M, Otto MW. A meta-analytic review of the effects of exercise on brain-derived neurotrophic factor. J Psychiatr Res (2015) 60:56-64. doi:10.1016/j.jpsychires.2014.10.003

27. Fabel K, Wolf SA, Ehninger D, Babu H, Leal-Galicia P, Kempermann G. Additive effects of physical exercise and environmental enrichment on adult hippocampal neurogenesis in mice. Front Neurosci (2009) 3:50. doi:10.3389/ neuro.22.002.2009

28. Eggenberger P, Schumacher V, Angst M, Theill N, de Bruin ED. Does multicomponent physical exercise with simultaneous cognitive training boost cognitive performance in older adults? A 6-month randomized controlled trial with a 1-year follow-up. Clin Interv Aging (2015) 10:1335-49. doi:10.2147/ CIA.S87732

29. Shah T, Verdile G, Sohrabi H, Campbell A, Putland E, Cheetham C, et al. A combination of physical activity and computerized brain training improves verbal memory and increases cerebral glucose metabolism in the elderly. Transl Psychiatry (2014) 4:e487. doi:10.1038/tp.2014.122

30. Rahe J, Petrelli A, Kaesberg S, Fink GR, Kessler J, Kalbe E. Effects of cognitive training with additional physical activity compared to pure cognitive training in healthy older adults. Clin Interv Aging (2015) 10:297-310. doi:10.2147/CIA. S74071

31. Oswald WDG, Rupprecht R, Hagen B. Differential effects of single versus combined cognitive and physical training with older adults: the SimA study in a 5-year perspective. Eur J Ageing (2006) 3:179-92. doi:10.1007/ s10433-006-0035-z

32. Wexler BE, Iseli M, Leon S, Zaggle W, Rush C, Goodman A, et al. Cognitive priming and cognitive training: immediate and far transfer to academic skills in children. Sci Rep (2016) 6:32859. doi:10.1038/srep32859

33. Rosenbaum S, Tiedemann A, Sherrington C, Curtis J, Ward PB. Physical activity interventions for people with mental illness: a systematic review and meta-analysis. J Clin Psychiatry (2014) 75(9):964-74. doi:10.4088/ JCP.13r08765

34. Acil AA, Dogan S, Dogan O. The effects of physical exercises to mental state and quality of life in patients with schizophrenia. J Psychiatr Ment Health Nurs (2008) 15(10):808-15. doi:10.1111/j.1365-2850.2008.01317.x

35. Svatkova A, Mandl RC, Scheewe TW, Cahn W, Kahn RS, Hulshoff Pol HE. Physical exercise keeps the brain connected: biking increases white matter integrity in patients with schizophrenia and healthy controls. Schizophr Bull (2015) 41(4):869-78. doi:10.1093/schbul/sbv033

36. Pajonk FG, Wobrock T, Gruber O, Scherk H, Berner D, Kaizl I, et al. Hippocampal plasticity in response to exercise in schizophrenia. Arch Gen Psychiatry (2010) 67(2):133-43. doi:10.1001/archgenpsychiatry.2009.193

37. Kimhy D, Vakhrusheva J, Bartels MN, Armstrong HF, Ballon JS, Khan S, et al. The impact of aerobic exercise on brain-derived neurotrophic factor and neurocognition in individuals with schizophrenia: a single-blind, randomized clinical trial. Schizophr Bull (2015) 41(4):859-68. doi:10.1093/schbul/ sbv022

38. Firth J, Stubbs B, Rosenbaum S, Vancampfort D, Malchow B, Schuch F, et al. Aerobic exercise improves cognitive functioning in people with schizophrenia: a systematic review and meta-analysis. Schizophr Bull (2017) 43(3):546-56. doi:10.1093/schbul/sbw115 
39. Oertel-Knochel V, Mehler P, Thiel C, Steinbrecher K, Malchow B, Tesky V, et al. Effects of aerobic exercise on cognitive performance and individual psychopathology in depressive and schizophrenia patients. Eur Arch Psychiatry Clin Neurosci (2014) 264(7):589-604. doi:10.1007/s00406-014-0485-9

40. MalchowB,KellerK,Hasan A,DorflerS,Schneider-Axmann T,Hillmer-VogelU, et al. Effects of endurance training combined with cognitive remediation on everyday functioning, symptoms, and cognition in multiepisode schizophrenia patients. Schizophr Bull (2015) 41(4):847-58. doi:10.1093/schbul/sbv020

41. Nuechterlein KH, Ventura J, McEwen SC, Gretchen-Doorly D, Vinogradov S, Subotnik KL. Enhancing cognitive training through aerobic exercise after a first schizophrenia episode: theoretical conception and pilot study. Schizophr Bull (2016) 42(Suppl 1):S44-52. doi:10.1093/schbul/sbw007

42. Dedoncker J, Brunoni AR, Baeken C, Vanderhasselt MA. The effect of the interval-between-sessions on prefrontal transcranial direct current stimulation (tDCS) on cognitive outcomes: a systematic review and meta-analysis. J Neural Transm (Vienna) (2016) 123(10):1159-72. doi:10.1007/s00702-016-1558-x

43. Hasan A, Strube W, Palm U, Wobrock T. Repetitive noninvasive brain stimulation to modulate cognitive functions in schizophrenia: a systematic review of primary and secondary outcomes. Schizophr Bull (2016) 42(Suppl 1):S95-109. doi:10.1093/schbul/sbv158

44. Dresler M, Sandberg A, Ohla K, Bublitz C, Trenado C, Mroczko-Wasowicz A, et al. Non-pharmacological cognitive enhancement. Neuropharmacology (2013) 64:529-43. doi:10.1016/j.neuropharm.2012.07.002

45. Nitsche MA, Cohen LG, Wassermann EM, Priori A, Lang N, Antal A, et al. Transcranial direct current stimulation: state of the art 2008. Brain Stimul (2008) 1(3):206-23. doi:10.1016/j.brs.2008.06.004

46. Priori A, Hallett M, Rothwell JC. Repetitive transcranial magnetic stimulation or transcranial direct current stimulation? Brain Stimul (2009) 2(4):241-5. doi:10.1016/j.brs.2009.02.004

47. Zaghi S, Acar M, Hultgren B, Boggio PS, Fregni F. Noninvasive brain stimulation with low-intensity electrical currents: putative mechanisms of action for direct and alternating current stimulation. Neuroscientist (2010) 16(3):285-307. doi:10.1177/1073858409336227

48. Nitsche MA, Paulus W. Excitability changes induced in the human motor cortex by weak transcranial direct current stimulation. J Physiol (2000) 527(Pt 3):633-9. doi:10.1111/j.1469-7793.2000.t01-1-00633.x

49. Wagner T, Fregni F, Fecteau S, Grodzinsky A, Zahn M, Pascual-Leone A. Transcranial direct current stimulation: a computer-based human model study. Neuroimage (2007) 35(3):1113-24. doi:10.1016/j.neuroimage.2007.01.027

50. Nitsche MA, Paulus W. Sustained excitability elevations induced by transcranial DC motor cortex stimulation in humans. Neurology (2001) 57(10):1899-901. doi:10.1212/WNL.57.10.1899

51. Stagg CJ, Best JG, Stephenson MC, O'Shea J, Wylezinska M, Kincses ZT, et al. Polarity-sensitive modulation of cortical neurotransmitters by transcranial stimulation. J Neurosci (2009) 29(16):5202-6. doi:10.1523/ JNEUROSCI.4432-08.2009

52. Reis J, Schambra HM, Cohen LG, Buch ER, Fritsch B, Zarahn E, et al. Noninvasive cortical stimulation enhances motor skill acquisition over multiple days through an effect on consolidation. Proc Natl Acad Sci U S A (2009) 106(5):1590-5. doi:10.1073/pnas.0805413106

53. Liebetanz D, Nitsche MA, Tergau F, Paulus W. Pharmacological approach to the mechanisms of transcranial DC-stimulation-induced after-effects of human motor cortex excitability. Brain (2002) 125(Pt 10):2238-47. doi:10.1093/brain/awf238

54. Fisher M, Loewy R, Hardy K, Schlosser D, Vinogradov S. Cognitive interventions targeting brain plasticity in the prodromal and early phases of schizophrenia. Annu Rev Clin Psychol (2013) 9:435-63. doi:10.1146/ annurev-clinpsy-032511-143134

55. Player MJ, Taylor JL, Weickert CS, Alonzo A, Sachdev PS, Martin D, et al. Increase in PAS-induced neuroplasticity after a treatment course of transcranial direct current stimulation for depression. JAffect Disord (2014) 167:140-7. doi:10.1016/j.jad.2014.05.063

56. Martin DM, Liu R, Alonzo A, Green M, Player MJ, Sachdev P, et al. Can transcranial direct current stimulation enhance outcomes from cognitive training? A randomized controlled trial in healthy participants. Int J Neuropsychopharmacol (2013) 16(9):1927-36. doi:10.1017/S1461145713000539

57. Andrews SC, Hoy KE, Enticott PG, Daskalakis ZJ, Fitzgerald PB. Improving working memory: the effect of combining cognitive activity and anodal transcranial direct current stimulation to the left dorsolateral prefrontal cortex. Brain Stimul (2011) 4(2):84-9. doi:10.1016/j.brs.2010.06.004

58. Ditye T, Jacobson L, Walsh V, Lavidor M. Modulating behavioral inhibition by tDCS combined with cognitive training. Exp Brain Res (2012) 219(3):363-8. doi:10.1007/s00221-012-3098-4

59. Park SH, Seo JH, Kim YH, Ko MH. Long-term effects of transcranial direct current stimulation combined with computer-assisted cognitive training in healthy older adults. Neuroreport (2014) 25(2):122-6. doi:10.1097/ WNR.0000000000000080

60. Cohen Kadosh R, Soskic S, Iuculano T, Kanai R, Walsh V. Modulating neuronal activity produces specific and long-lasting changes in numerical competence. Curr Biol (2010) 20(22):2016-20. doi:10.1016/j.cub.2010.10.007

61. Hoy KE, Arnold SL, Emonson MR, Daskalakis ZJ, Fitzgerald PB. An investigation into the effects of tDCS dose on cognitive performance over time in patients with schizophrenia. Schizophr Res (2014) 155(1-3):96-100. doi:10.1016/j.schres.2014.03.006

62. Vercammen A, Rushby JA, Loo C, Short B, Weickert CS, Weickert TW. Transcranial direct current stimulation influences probabilistic association learning in schizophrenia. Schizophr Res (2011) 131(1-3):198-205. doi:10.1016/j.schres.2011.06.021

63. Smith RC, Boules S, Mattiuz S, Youssef M, Tobe RH, Sershen H, et al. Effects of transcranial direct current stimulation (tDCS) on cognition, symptoms, and smoking in schizophrenia: a randomized controlled study. Schizophr Res (2015) 168(1-2):260-6. doi:10.1016/j.schres.2015.06.011

64. Brunelin J, Mondino M, Gassab L, Haesebaert F, Gaha L, Suaud-Chagny MF, et al. Examining transcranial direct-current stimulation (tDCS) as a treatment for hallucinations in schizophrenia. Am J Psychiatry (2012) 169(7):719-24. doi:10.1176/appi.ajp.2012.11071091

65. Mondino M, Jardri R, Suaud-Chagny MF, Saoud M, Poulet E, Brunelin J. Effects of fronto-temporal transcranial direct current stimulation on auditory verbal hallucinations and resting-state functional connectivity of the left temporo-parietal junction in patients with schizophrenia. Schizophr Bull (2016) 42(2):318-26. doi:10.1093/schbul/sbv114

66. Palm U, Keeser D, Hasan A, Kupka MJ, Blautzik J, Sarubin N, et al. Prefrontal transcranial direct current stimulation for treatment of schizophrenia with predominant negative symptoms: a double-blind, sham-controlled proofof-concept study. Schizophr Bull (2016) 42(5):1253-61. doi:10.1093/schbul/ sbw041

67. Dunn W, Rassovsky Y, Wynn JK, Wu AD, Iacoboni M, Hellemann G, et al. Modulation of neurophysiological auditory processing measures by bilateral transcranial direct current stimulation in schizophrenia. Schizophr Res (2016) 174(1-3):189-91. doi:10.1016/j.schres.2016.04.021

68. Tarur Padinjareveettil AM, Rogers J, Loo C, Martin D. Transcranial direct current stimulation to enhance cognitive remediation in schizophrenia. Brain Stimul (2015) 8(2):307-9. doi:10.1016/j.brs.2014.11.012

69. Nienow TM, MacDonald AW III, Lim KO. TDCS produces incremental gain when combined with working memory training in patients with schizophrenia: a proof of concept pilot study. Schizophr Res (2016) 172(1-3):218-9. doi:10.1016/j.schres.2016.01.053

70. Shiozawa P, Gomes JS, Ducos DV, Akiba HT, Dias AM, Trevizol AP, et al. Effect of transcranial direct current stimulation (tDCS) over the prefrontal cortex combined with cognitive training for treating schizophrenia: a sham-controlled randomized clinical trial. Trends Psychiatry Psychother (2016) 38(3):175-7. doi:10.1590/2237-6089-2015-0043

71. Orlov ND, Tracy DK, Joyce D, Patel S, Rodzinka-Pasko J, Dolan H, et al. Stimulating cognition in schizophrenia: a controlled pilot study of the effects of prefrontal transcranial direct current stimulation upon memory and learning. Brain Stimul (2017) 10(3):560-6. doi:10.1016/j.brs.2016.12.013

72. Dauwan M, Begemann MJ, Heringa SM, Sommer IE. Exercise improves clinical symptoms, quality of life, global functioning, and depression in schizophrenia: a systematic review and meta-analysis. Schizophr Bull (2016) 42(3):588-99. doi:10.1093/schbul/sbv164

73. Bhatia T, Mazumdar S, Wood J, He F, Gur RE, Gur RC, et al. A randomised controlled trial of adjunctive yoga and adjunctive physical exercise training for cognitive dysfunction in schizophrenia. Acta Neuropsychiatr (2017) 29(2):102-14. doi:10.1017/neu.2016.42

74. Robinson MM,DasariS, Konopka AR, Johnson ML, ManjunathaS, Esponda RR, et al. Enhanced protein translation underlies improved metabolic and physical 
adaptations to different exercise training modes in young and old humans. Cell Metab (2017) 25(3):581-92. doi:10.1016/j.cmet.2017.02.009

75. Strassnig MT, Signorile JF, Potiaumpai M, Romero MA, Gonzalez C, Czaja S, et al. High velocity circuit resistance training improves cognition, psychiatric symptoms and neuromuscular performance in overweight outpatients with severe mental illness. Psychiatry Res (2015) 229(1-2):295-301. doi:10.1016/j. psychres.2015.07.007

76. Kimhy D, Lauriola V, Bartels MN, Armstrong HF, Vakhrusheva J, Ballon JS, et al. Aerobic exercise for cognitive deficits in schizophrenia - the impact of frequency, duration, and fidelity with target training intensity. Schizophr Res (2016) 172(1-3):213-5. doi:10.1016/j.schres.2016.01.055

77. Stanton R, Happell B. A systematic review of the aerobic exercise program variables for people with schizophrenia. Curr Sports Med Rep (2014) 13(4):260-6. doi:10.1249/JSR.0000000000000069

78. Garber CE, Blissmer B, Deschenes MR, Franklin BA, Lamonte MJ, Lee IM, et al. American College of Sports Medicine position stand. Quantity and quality of exercise for developing and maintaining cardiorespiratory, musculoskeletal, and neuromotor fitness in apparently healthy adults: guidance for prescribing exercise. Med Sci Sports Exerc (2011) 43(7):1334-59. doi:10.1249/ MSS.0b013e318213fefb

79. Campos C, Rocha NB, Nardi AE, Lattari E, Machado S. Exercise induced neuroplasticity to enhance therapeutic outcomes of cognitive remediation in schizophrenia: analyzing the role of brain-derived neurotrophic factor. CNS Neurol Disord Drug Targets (2017) 16(6):638-51. doi:10.2174/187152731566 6161223142918

80. Floel A, Cohen LG. Contribution of noninvasive cortical stimulation to the study of memory functions. Brain Res Rev (2007) 53(2):250-9. doi:10.1016/j. brainresrev.2006.08.006

81. Kandola A, Hendrikse J, Lucassen PJ, Yucel M. Aerobic exercise as a tool to improve hippocampal plasticity and function in humans: practical implications for mental health treatment. Front Hum Neurosci (2016) 10:373. doi:10.3389/fnhum.2016.00373

82. Heynen AJ, Bear MF. Long-term potentiation of thalamocortical transmission in the adult visual cortex in vivo. J Neurosci (2001) 21(24):9801-13.

83. Clapp WC, Hamm JP, Kirk IJ, Teyler TJ. Translating long-term potentiation from animals to humans: a novel method for noninvasive assessment of cortical plasticity. Biol Psychiatry (2012) 71(6):496-502. doi:10.1016/j. biopsych.2011.08.021

84. McNair NA, Clapp WC, Hamm JP, Teyler TJ, Corballis MC, Kirk IJ. Spatial frequency-specific potentiation of human visual-evoked potentials. Neuroreport (2006) 17(7):739-41. doi:10.1097/01. wnr.0000215775.53732.9f

85. Mears RP, Spencer KM. Electrophysiological assessment of auditory stimulus-specific plasticity in schizophrenia. Biol Psychiatry (2012) 71(6):503-11. doi:10.1016/j.biopsych.2011.12.016

86. Ross RM, McNair NA, Fairhall SL, Clapp WC, Hamm JP, Teyler TJ, et al. Induction of orientation-specific LTP-like changes in human visual evoked potentials by rapid sensory stimulation. Brain Res Bull (2008) 76(1-2):97-101. doi:10.1016/j.brainresbull.2008.01.021

87. Teyler TJ, Hamm JP, Clapp WC, Johnson BW, Corballis MC, Kirk IJ. Longterm potentiation of human visual evoked responses. Eur J Neurosci (2005) 21(7):2045-50. doi:10.1111/j.1460-9568.2005.04007.x

88. Cavus I, Reinhart RM, Roach BJ, Gueorguieva R, Teyler TJ, Clapp WC, et al. Impaired visual cortical plasticity in schizophrenia. Biol Psychiatry (2012) 71(6):512-20. doi:10.1016/j.biopsych.2012.01.013

89. Jahshan C, Wynn JK, Mathalon DH, Green MF. Cognitive correlates of visual neural plasticity in schizophrenia. Schizophr Res (2017). doi:10.1016/j. schres.2017.03.016

Conflict of Interest Statement: The authors declare that the research was conducted in the absence of any commercial or financial relationships that could be construed as a potential conflict of interest.

The reviewers SI and ZN and handling editor declared their shared affiliation.

Copyright () 2017 Jahshan, Rassovsky and Green. This is an open-access article distributed under the terms of the Creative Commons Attribution License (CC BY). The use, distribution or reproduction in other forums is permitted, provided the original author(s) or licensor are credited and that the original publication in this journal is cited, in accordance with accepted academic practice. No use, distribution or reproduction is permitted which does not comply with these terms. 